\title{
Preparation of network $\pi$-conjugated copolymers with Ullmann type polycondensation
}

\author{
Kuniharu Nakajima, Hiromasa Goto* \\ Division of Materials Science, Faculty of Pure and Applied Sciences, University of Tsukuba, \\ Tsukuba, Ibaraki 305-8573, Japan \\ *E-mail address: gotoh@ims.tsukuba.ac.jp
}

\begin{abstract}
Ullmann type polycondensations in the presence of $\mathrm{CuI}$ and a base were carried out to afford network type $\pi$-conjugated copolymers. Infrared absorption spectroscopy measurements and surface observation using a scanning electron microscopy are carried out. Electron spin resonance spectroscopy measurements revealed that the cross-linked copolymers thus obtained contain small amount of copper. This polymerization conveniently allows production of network $\pi$-conjugated polymers. The polymer can be expected to have thermo-resistance.
\end{abstract}

Keywords: copolymer; cross-link; polyaniline; Ullmann reaction

\section{INTRODUCTION}

Polyaniline (PANI) [1] is one of the most promising conducting polymers because it has relatively high conductivity, and processability. PANI has been applied for sensors [2], anti-corrosion agent, and buffer layer for O-LED, electrochromics, and anti-static materials.

Ullmann condensation reaction is widely known as a coupling reaction by using copper. Especially, this is quite useful for condensation reaction between amine and halogen to synthesize $\pi$-conjugated compounds. To obtain polyaniline (PANI), oxidative polycondensation with ammonium persulfate (APS) in the water has been employed. This method allows production of PANI in the form of doped state (emeraldine salt). Ullmann polycondensation [3] of $m$-chloro-aniline and $m$-dibromobenzene allows poly $(m$-aniline $)$ [4]. Buchwald-Hartwig reaction with an aid of Pd catalyst allows reaction of aniline and halogen substituted aromatic group [5,6]. Palladium-catalyzed polycondensation of aryl dibromides with aryl primary diamines has been performed to afford linear polymers [7].

Classic Ullmann reaction has advantages for condensation reaction because low cost and the reaction can be conducted in the air, although high reaction temperature is required. The Ullmann polycondensation reaction can afford tertiary amines to give network polymers. Natural network polymers such as lignin have high strength. Phenol resin as a synthetic network polymers has been widely applied in industry. Therefore, network type $\pi$-conjugated polymers can be expected for mechanical strength, durability, and electronic property derived from the $\pi$-electrons. In this research, we perform Ullmann type polycondensation to obtain network poly(arylene-co-polyaniline)s. Infrared absorption (IR) spectroscopy measurements, 
surface observation using a scanning electron (SEM) microscopy, electron spin resonance (ESR), and UV-VIS optical absorption spectroscopy measurements are carried out for the polymers thus obtained.

\section{EXPERIMENT}

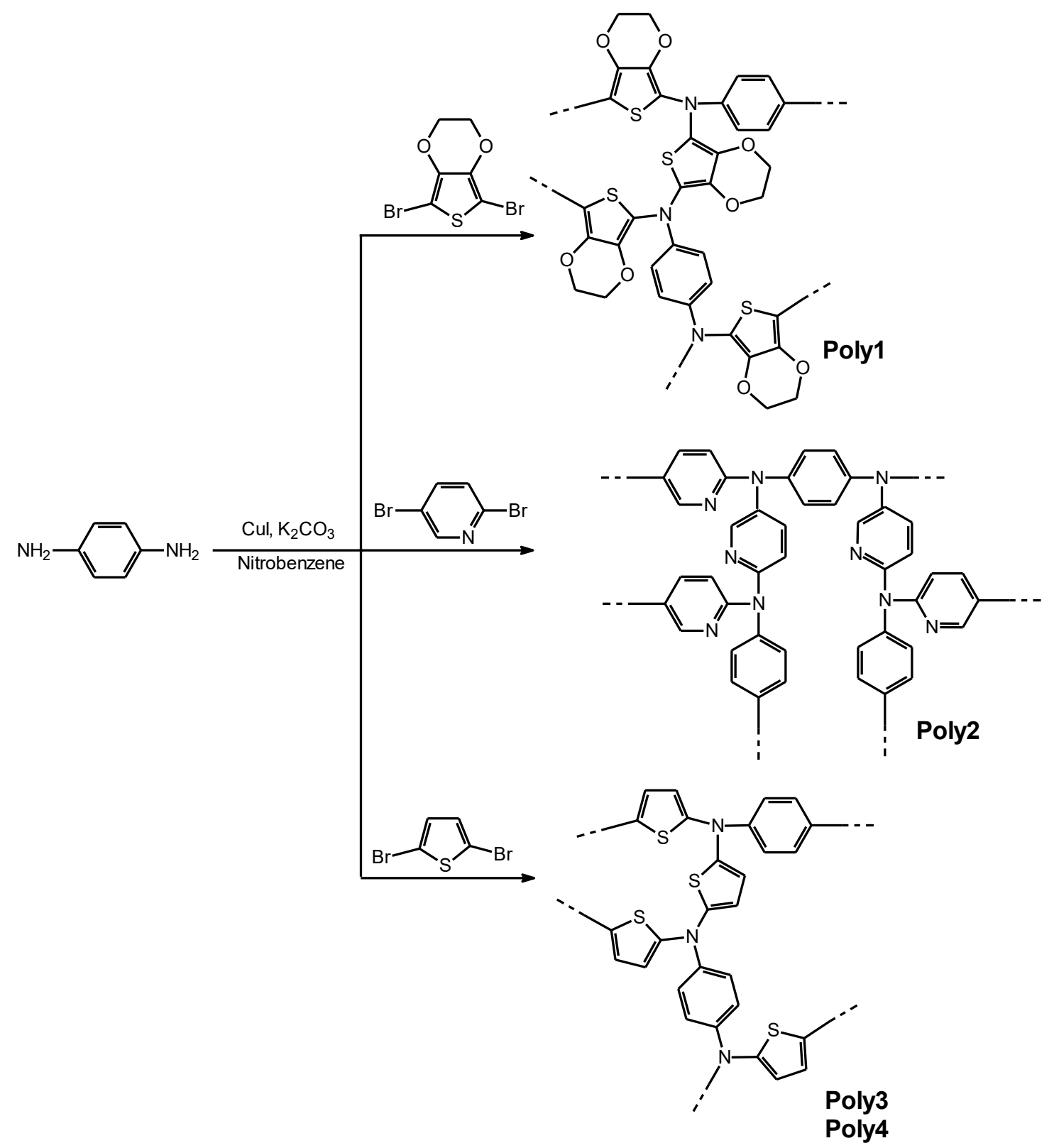

Scheme 1. Synthesis of network polymers.

Poly1, quantity used: $\operatorname{EDOTBr}_{2}(0.1 \mathrm{~g}, 0.335 \mathrm{mmol}), p$-phenylenediamine $(0.36 \mathrm{~g}, 0.335 \mathrm{mmol})$, nitrobenzene $(1 \mathrm{~mL}), \mathrm{CuI}\left(6.5 \mathrm{mg}, 3.4 \times 10^{-5} \mathrm{~mol}\right), \mathrm{K}_{2} \mathrm{CO}_{3}\left(46 \mathrm{mg}, 3.3 \times 10^{-4} \mathrm{~mol}\right) . \mathrm{Y}=0.081 \mathrm{~g}$.

Poly2, quantity used: 2,5-Dibromopyridine $(0.5 \mathrm{~g}, 2.1 \mathrm{mmol}), p$-phenylenediamine $(0.23 \mathrm{~g}, 2.1 \mathrm{mmol})$, nitrobenzene $(5 \mathrm{~mL})$, $\mathrm{CuI}\left(0.02 \mathrm{~g}, 1.05 \times 10^{-4} \mathrm{~mol}\right), \mathrm{K}_{2} \mathrm{CO}_{3}(0.3 \mathrm{~g}, 2.1 \mathrm{mmol})$. Y $=0.385 \mathrm{~g}$.

Poly3, quantity used: 2,5-Dibromothiophene (3 g, $0.012 \mathrm{~mol}), p$-phenylenediamine (1.34 g, $0.012 \mathrm{~mol})$, nitrobenzene $(20 \mathrm{~mL}), \mathrm{CuI}\left(0.2 \mathrm{~g}, 1.05 \times 10^{-3} \mathrm{~mol}\right), \mathrm{K}_{2} \mathrm{CO}_{3}(1.66 \mathrm{~g}, 0.012 \mathrm{mmol}) . \mathrm{Y}=0.920 \mathrm{~g}$.

Poly4, quantity used: 2,5-Dibromothiophene (3 g, $0.012 \mathrm{~mol}), p$-phenylenediamine $(1.34 \mathrm{~g}, 0.012 \mathrm{~mol})$, nitrobenzene $(20 \mathrm{~mL}), \mathrm{CuI}\left(0.02 \mathrm{~g}, 1.05 \times 10^{-4} \mathrm{~mol}\right), \mathrm{K}_{2} \mathrm{CO}_{3}(1.66 \mathrm{~g}, 0.012 \mathrm{mmol}) . \mathrm{Y}=0.958 \mathrm{~g}$. 
Polymerization was conducted between dibromoarylene, such as dibromo-3,4-ethylenediioxythiophene $\left(\mathrm{EDOTBr}_{2}\right), \quad 2,5$-dibromothiophene, or 2,5-dibromopyridine), and $p$-phenylenediamine as shown in Scheme 1. A solution of the dibromoalyrene, dibromobenzene, and $\mathrm{K}_{2} \mathrm{CO}_{3}$ in nitrobenzene was stirred for $24 \mathrm{~h}$ at $140{ }^{\circ} \mathrm{C}$. Then, the reaction mixture was poured into a large volume of methanol. After filtration, the product was washed with a large volume of distilled water, and a large volume of methanol again. Filtration followed by drying in vacuum yielded network copolymers. The copolymers thus obtained are abbreviated as Poly1 (poly(EDOT-aniline), Poly2 (pyridine-aniline), Poly3 (thiophene-aniline). The copolymers are infusible because of formation of polymer network by cross-link.

\section{RESULTS AND DISCUSSION}

\section{1. IR}

IR absorption spectroscopy measurements were carried out with the $\mathrm{KBr}$ method (Figure 1). Poly1 shows absorption bands at $1628 \mathrm{~cm}^{-1}$ ( $\mathrm{C}=\mathrm{C}$ stretching, quinonoid) [8], 1518 $\mathrm{cm}^{-1}$ ( $\mathrm{C}=\mathrm{C}$ stretching, benzenoid), and $1089 \mathrm{~cm}^{-1}$ (C-O-C, stretching, benzenoid). An absorption bands at around $3300 \mathrm{~cm}^{-1}$ due to N-H stretching was not observed. Wide range absorption from $4000-2000 \mathrm{~cm}^{-1}$ indicates that the polymer is doped state. Poly4 shows the same absorption bands as Poly3.

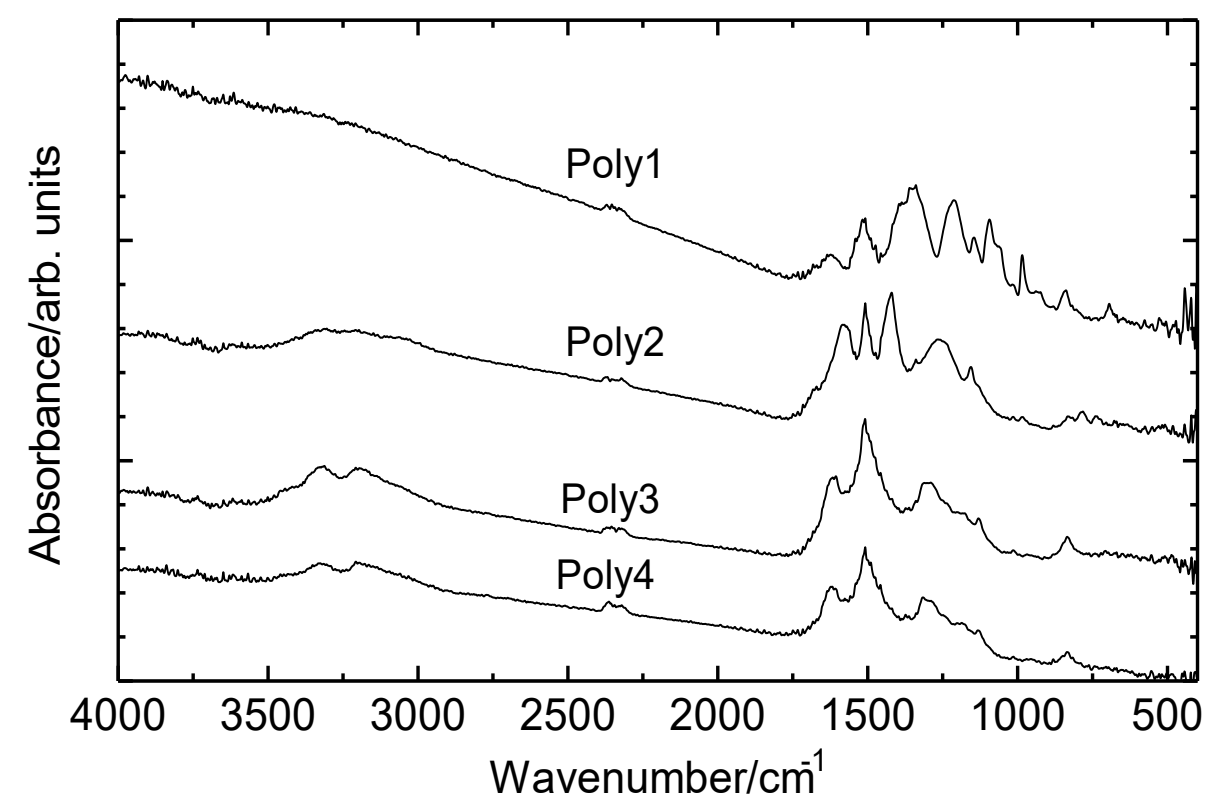

Figure 1. Infrared absorption spectra of the polymers.

$\mathrm{HBr}$ yielded during the reaction functioned to be a dopant to the resultant polymer $\left(\mathrm{K}_{2} \mathrm{CO}_{3}\right.$ in the reaction may not neutralize it).

Poly1 shows electrical conductivity of $9.0 \times 10^{-3} \mathrm{~S} / \mathrm{cm}$. Poly2 and Poly3 display absorption bands at long wavenumber due to N-H stretching, absorption at 3233, 3319, 3184 . Poly2 (IR, $\left.\mathrm{cm}^{-1}\right): 3233$ (N-H stretching), $1579(\mathrm{C}=\mathrm{C}$ stretching, quinonoid), $1505(\mathrm{C}=\mathrm{C}$ stretching, benzenoid), 1420, 1260 (aromatic ring stretching). 
Poly3 (IR, $\mathrm{cm}^{-1}$ ): 3319 and 3184 (N-H stretching), 1616, 1505, $1303 \mathrm{~cm}^{-1}$ (aromatic ring stretching).

\section{2. SEM}

Figures 2,3 show surface structure of the polymers. These polymers exhibit pebbles like structure $[9,10]$. Poly3 partly displays bubble-like structure.

\section{3. ESR}

Electron spin resonance (ESR) measurements were carried out for the powder of the polymers [11]. Polymers show the ESR signals at around $g=2.08$. Spin numbers of the polymers are to be in the range of 7-9 $\times 10^{-6} \mathrm{spins} / \mathrm{g}$. However, an ESR signal due to paramagnetic copper was overlapped on the polymers signal. This result indicates that removal of the trace amount of copper as a catalyst from the resultant polymer seems to be difficult.

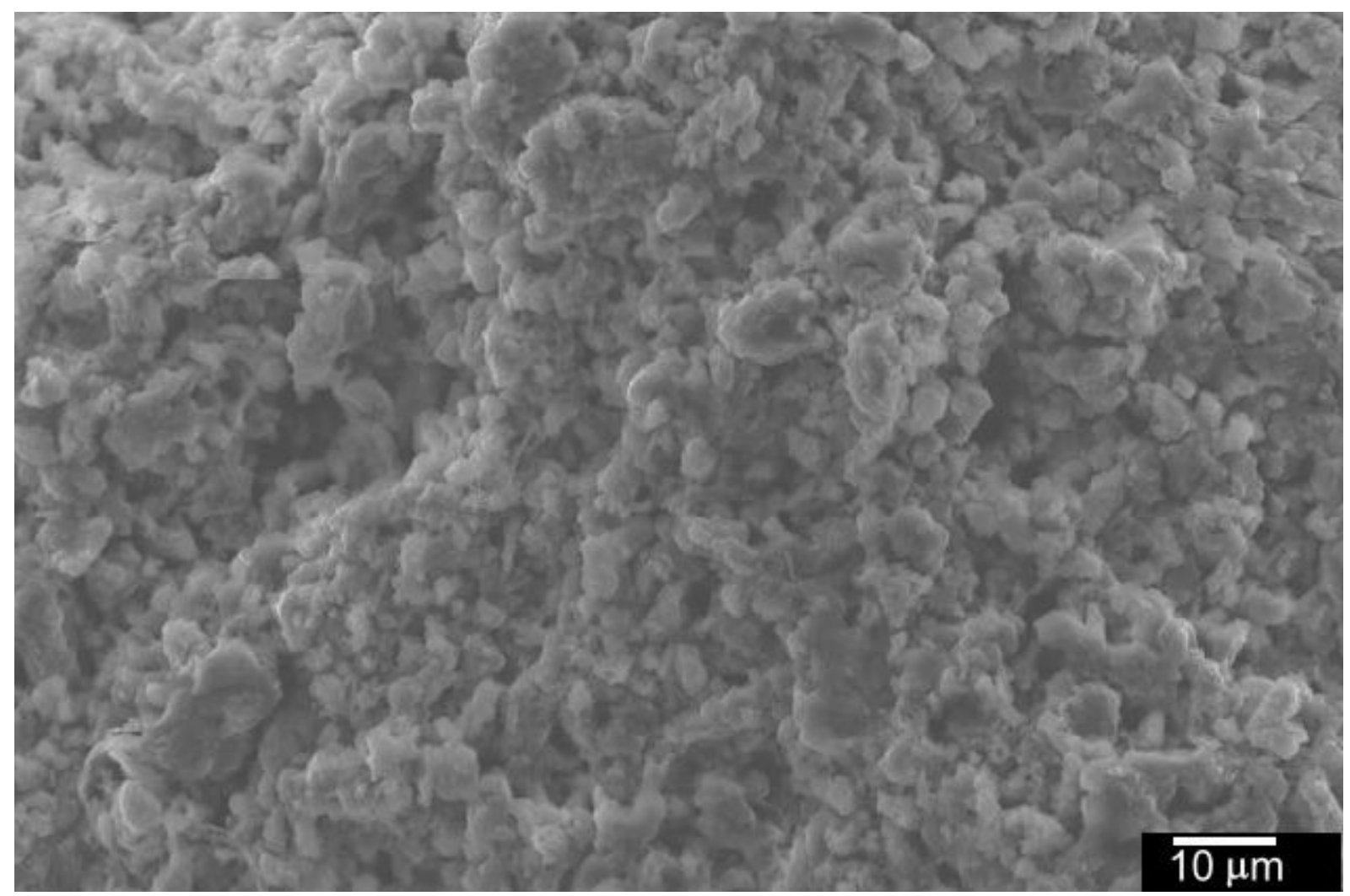

Figure 2. Scanning electron microscopy (SEM) images of Poly2 $(1,000 \times)$. 


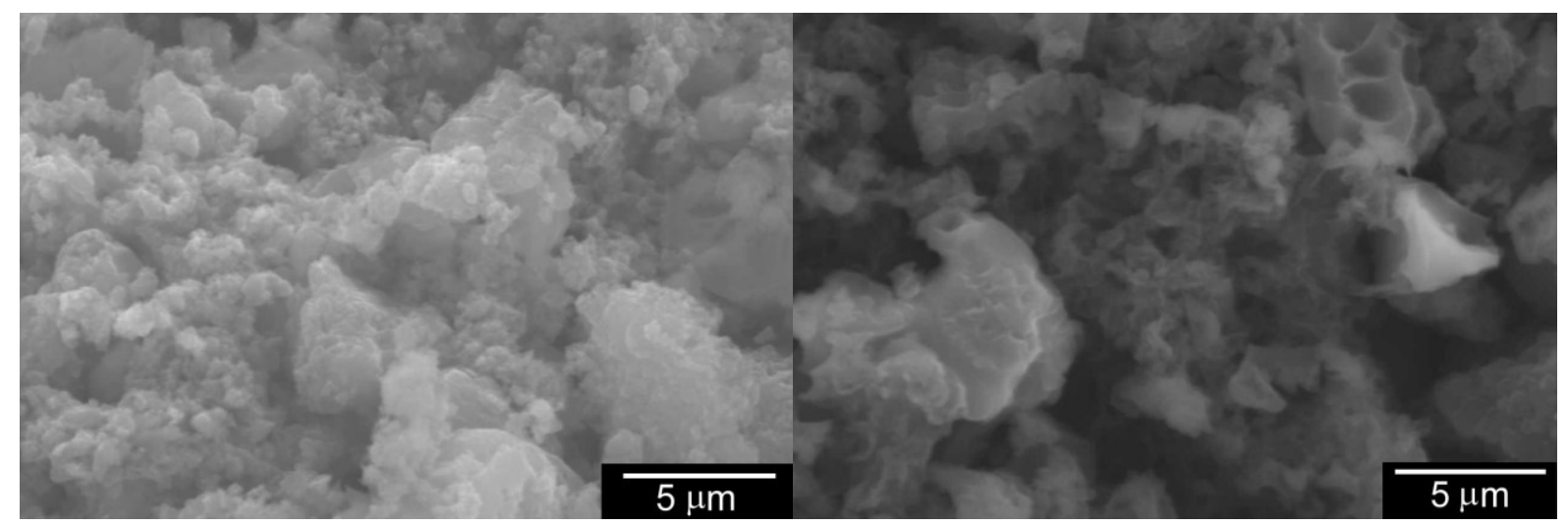

Figure 3. SEM images of Poly1 (left, 5,000×) and Poly3 (right, 5,000×).

\section{4. UV-VIS}

The polymers are slightly soluble in $N$-methyl pyrrolidone (NMP). The UV-VIS optical absorption spectra of the polymers are shown in Figure 4 . These polymers display an absorption band at $540 \mathrm{~nm}$ except Poly2 (sh, $698 \mathrm{~nm}$ ) due to $\pi-\pi^{*}$ transition of the main skeleton [12]. This result demonstrates that the network polymers are consisting of $\pi$-conjugate system.

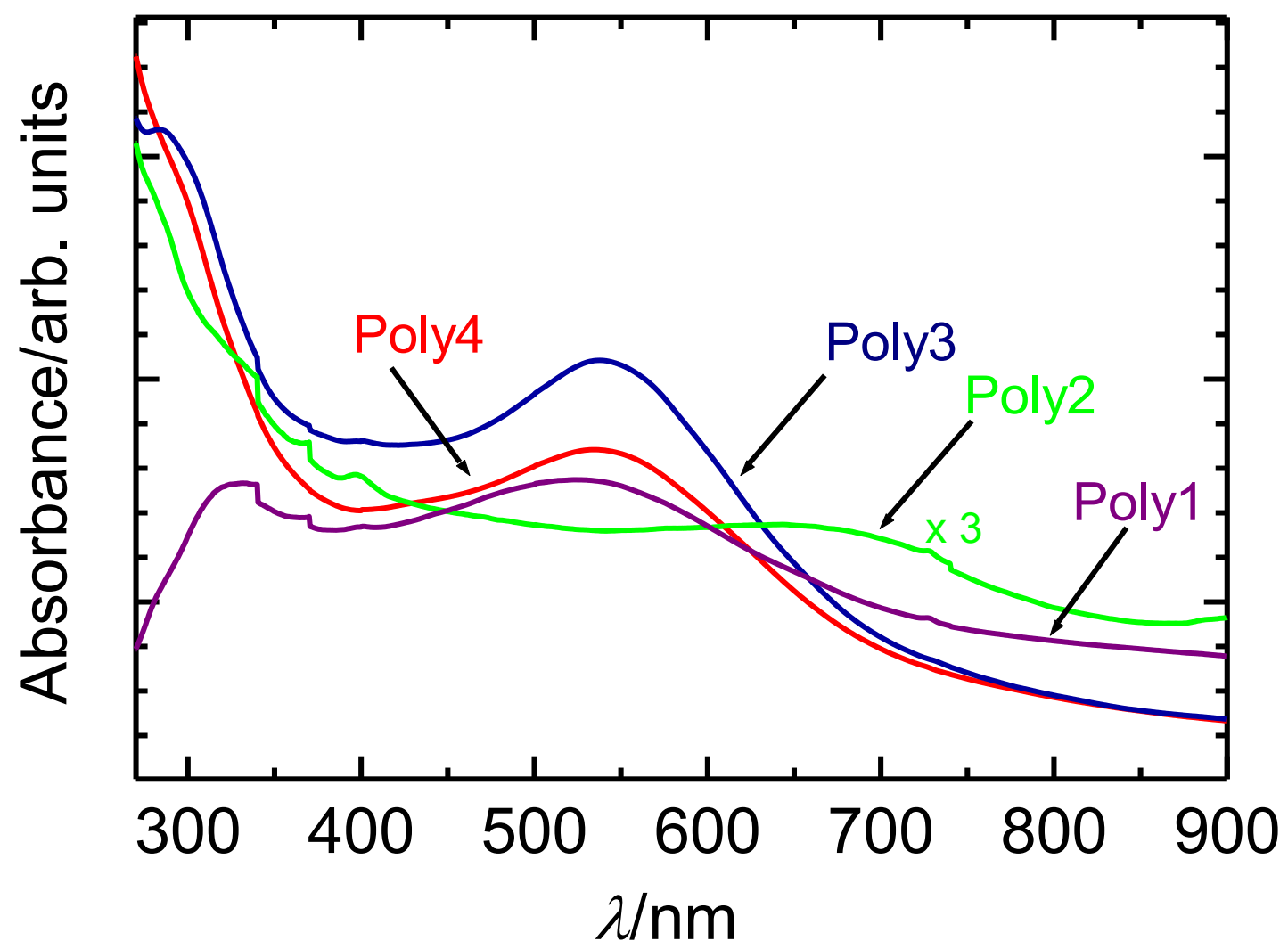

Figure 4. UV-VIS optical absorption spectra of the polymers in $N$-methyl pyrolidone solutions. 


\section{CONCLUSIONS}

Ullmann polycondensation reaction for formation of tertiary amine allows network copolymers consisting of arylene (EDOT, pyridine, and thiophene) and aniline units. The structures were confirmed using IR absorption spectroscopy measurements. Surface structure of the polymers was observed using a SEM. The $\pi$-conjugated network polymers thus obtained may be useful for thermo-resistance materials, sensors, and antistatic organic materials.

\section{INSTRUMENTS}

IR spectroscopy measurements were conducted using a FT-IR 550 spectrometer (JASCO, Japan). ESR spectroscopy measurements were carried out using a JEOL JES TE-200 spectrometer with $100 \mathrm{kHz}$ modulation. SEM observations were carried out with JEOL JSM-521. UV-VIS absorption spectroscopy measurements were conducted using a V-630 (JASCO).

\section{References}

[1] J. C. Chiang, A. G. MacDiarmid, Synth. Met. 13 (1986) 193-205.

[2] I. Michira, R. Akinyeye, V. Somerset, M. J. Klink, M. Sekota, A. Al-Ahmed, P. G. L. Baker, E. Iwuoha, Macromol. Symp. 255 (2007) 57-69.

[3] E. Sperotto, G. P. M. van Klink, G. van Koten, J. G. de Vries, Dalton Trans. 39 (2010), 10338-10351.

[4] K. Yoshizawa, K. Tanaka, T. Yamabe, Chem. Lett. (1991) 1311-1314.

[5] F. Paul, J. Patt, J. F. Hartwig, J. Am Chem Soc. 116 (1994) 5969-5970.

[6] A. S.Guram, S. L. Buchwald, J. Am Chem Soc 116 (1994) 7901-7902.

[7] T. Kanbara Y. Nakadani, K. Hasegawa, Polym. J. 31 (1999) 206-209.

[8] H. Goto, J. Hot Spring Sci. 60 (2010) 134-144.

[9] H Goto, A. Yokoo, J. Disp. Sci. Technol. 34 (2013) 406-410.

[10] J. Stejskal, I. Sapurina, M. Trchová, E. N. Konyushenko, Macromolecules 41 (2008) 3530-3536.

[11] H. H. S. Javidi, R. Laversanne, A. J. Epstein, Synth. Met. 29 (1989) E439-E444.

[12] C. K. Tan, D. J. Blackwood, Sens. Actuat. B, 71 (2000) 184-191. 